\title{
Article \\ Effects of Experimental Parameters on Condensation Heat Transfer in Plate Fin Heat Exchanger
}

\author{
Sung-Hoon Seol ${ }^{1}$, , Sun-Geun Lee ${ }^{1}$, Chang-Hyo Son ${ }^{1}$, Ji-Hoon Yoon ${ }^{1}$, In-Seob Eom ${ }^{2}$, Young-Min Park ${ }^{2}$ \\ and Jung-In Yoon ${ }^{1, *}$ \\ 1 Department of Refrigeration and Air-Conditioning Engineering, College of Engineering, \\ Pukyong National University, Busan 48513, Korea; seolsh@pknu.ac.kr (S.-H.S.); \\ tjsrms0206@naver.com (S.-G.L.); sonch@pknu.ac.kr (C.-H.S.); neverzksch@naver.com (J.-H.Y.) \\ 2 R\&D Center, DongHwa Entec, Busan 46742, Korea; eis@dh.co.kr (I.-S.E.); pym@dh.co.kr (Y.-M.P.) \\ * Correspondence: yoonji@pknu.ac.kr; Tel.: +82-51-629-6180
}

check for updates

Citation: Seol, S.-H.; Lee, S.-G.; Son, C.-H.; Yoon, J.-H.; Eom, I.-S.; Park, Y.-M.; Yoon, J.-I. Effects of Experimental Parameters on Condensation Heat Transfer in Plate Fin Heat Exchanger. Energies 2021, 14, 7681. https://doi. org/10.3390/en14227681

Academic Editor: Dmitry Eskin

Received: 21 October 2021

Accepted: 13 November 2021

Published: 17 November 2021

Publisher's Note: MDPI stays neutral with regard to jurisdictional claims in published maps and institutional affiliations.

Copyright: (c) 2021 by the authors. Licensee MDPI, Basel, Switzerland. This article is an open access article distributed under the terms and conditions of the Creative Commons Attribution (CC BY) license (https:// creativecommons.org/licenses/by/ $4.0 /)$.

\begin{abstract}
This study aims to provide an experimental investigation and comparison of the condensation heat transfer characteristics in a plate-fin heat exchanger (PFHE). The heat flux, mass flux, and saturation pressure were adjusted as experimental parameters to verify the effects on the condensation heat transfer. In addition, condensation heat transfer correlation of two-stream PFHEs was provided based on the experimental data for utilization as a design reference for the heat exchanger. The turbulence is the most influential in heat transfer. One of the ways to foster turbulence is to increase shear stress. The higher flow velocity results in the higher shear stress. That was why increasing mass flux or the flow with higher vapor quality showed the higher heat transfer coefficient (HTC). Refrigerant properties such as viscosity and specific volume of vapor changed according to the saturation pressure. It is expected they affect the degree of turbulence too in similar manners. The mass flux was more influential than the heat flux and saturation pressure. Thus, the equivalent mass flux of the refrigerant is dominant in the derived correlation model. The average difference between experimental and calculated HTC from correlations was about $6.5 \%$. Multi-stream PFHE comprises an additional heat transfer surface, which implies a more active droplet formation. The average pressure drop in the multi-stream is $15 \%$ larger than that of the two-stream.
\end{abstract}

Keywords: condensation heat transfer; heat transfer correlation; Wilson plot method; plate-fin heat exchanger (PFHE); multi-stream PFHE

\section{Introduction}

The thermal performance enhancement of heat exchangers, which are essentially used in almost all types of thermal processes, has been considered a key topic owing to an interest in global energy efficiency enhancement. Therefore, the importance of two-phase heat transfer, in which the heat transfer performance is superior compared to single-phase heat transfer, has been emphasized [1-4]. Raju et al. [5] studied the evaporation heat transfer of R-134a and the pressure drop at a plate-fin heat exchanger (PFHE) with wavy fins. The results regarding the heat transfer showed that the heat transfer coefficient (HTC) increased as the heat flux increased, but its effect on the pressure drop was not notable. In addition, the condensation HTCs were significantly higher than the values obtained from the generally suggested correlation of condensation heat transfer, indicating that a proper correlation equation may be required. Sakamatapan et al. [6] reported the condensation heat transfer characteristics of R-134a in multiport mini channels based on thermal and geometric properties. From their research, it was found that the condensation HTC tends to increase with increasing mass flux and heat flux. Conversely, a smaller hydraulic diameter resulted in an increase in condensation HTC. Yan et al. [7] conducted research on the characteristics of plate heat exchangers, and the results indicated that an increase in the saturation pressure led to a decrease in the condensation HTC. However, 
similar to the study by Raju et al. [5], the effect on the pressure drop was relatively trivial. They also suggested correlation equations based on the experimental data. The case of the plate heat exchanger presented a higher HTC and pressure drop compared to the value calculated from the correlation equation for the cylindrical heat exchanger under the same conditions. Aliabadi et al. [8] analyzed the condensation heat transfer characteristics according to geometry of fins by using a simulation program: plain, wavy, and serrated fin. They revealed that the wavy fin presented the higher condensation HTC than the serrated fin. Meanwhile, single phase heat transfer is usually described as a function of Reynolds number, Prandtl number, and a correction factor which depends on the geometric parameter of the heat exchanger [9,10]. Khan et al. [11] presented a generalized Nusselt number correlation considering geometric characteristics of the twisted oval tube heat exchanger. It considers pin pitches, tube rows, number of tubes, etc. Two-phase refrigerant flows are often analyzed by homogeneous models which assumes that specific volume of the vapor-liquid mixture in the refrigerant channel is mixed homogeneously [7,12].

Heat exchangers with a surface density of $700 \mathrm{~m}^{2} / \mathrm{m}^{3}$ are usually called compact heat exchangers. Among them, PFHEs have the advantage of applying various fin geometries and a relatively simple design of the multi-stream $[13,14]$. Relevant analysis on the geometric characteristics of the fins or PFHE can be found in the research of Guo et al. [15]. Multi-stream structures result in more efficient utilization of the energy contained by fluids compared to two-stream heat exchangers, which is favorable in terms of high-efficiency heat transfer. Because of this, PFHEs are being utilized in various fields, such as Heating Ventilating and air conditioning (HVAC), aircraft, and cryogenic systems, in which compact and high-efficiency heat transfer is required $[16,17]$. Previous research related to multi-stream heat transfer is as follows. Prasad [18] conducted theoretical modeling of heat transfer through both sides of fins, where different temperature levels are formed. The research revealed that the heat transfer across the fins is affected by the temperature difference between the two side plates, meaning that modified fin efficiency equations for reflecting it should be applied to the model. The same author [19] also conducted research on the rating of multi-stream PFHE reflecting the modified fin efficiency, as mentioned above, and presented the comparison result between the case with ideal fin efficiency and that with the modified fin efficiency. In the "flow area," the ideal fin efficiency did not differ significantly from the case reflecting the modified fin efficiency, provided the temperature difference between both sides of the fin was not too large. However, notable differences were found in the "dummy area" where the flow does not go through. Sunden and Wang [20] focused on the fact that the Colburn j-factor and f-factor are dependent on the Reynolds number to present the design method of the multi-stream PFHE when convective HTC is known. It was also shown that multi-stream PFHE can be effectively designed by applying pinch technology, which utilizes the minimum temperature difference between fluids. Kay et al. analyzed the Colburn J-factors and f-factors of the single-phase heat transfer at various geometries of heat exchanger fins, and they reported that heat transfer and pressure drop characteristics change according to the shape of the fins and hydraulic diameter [21].

From the previous studies above, it can be concluded that the heat transfer in the two-phase zone tends to be affected by the mass flux, heat flux, saturation pressure, and geometric characteristics of the heat exchangers. In addition, the research on heat transfer in the case of PFHE is not sufficient compared to that of other types of heat exchangers. In particular, there are few studies on the phase-changing heat transfer characteristics in multistream PFHEs. The heat transfer characteristics in multi-stream PFHEs are completely different from those of two-stream PFHEs because of the presence of surfaces with different heat flux conditions.

Therefore, this research aims to provide an experimental investigation and comparison of the condensation heat transfer characteristics in PFHE. The heat flux, mass flux, and saturation pressure were adjusted as experimental parameters to verify the effects on the condensation heat transfer and determine the most influential factor among them. 
Finally, condensation heat transfer correlation of two-stream was provided based on the experimental data to be utilized as a design reference for the heat exchanger.

\section{Experimental System}

\subsection{Plate-Fin Heat Exchanger (PFHE)}

PFHE is a type of compact heat exchanger that comprises a stack of alternate flat plates called parting sheets and corrugated fins brazed together as a block [22]. Because of its geometric characteristics, it increases the heat transfer rate with less volume and weight than other heat exchangers [23]. Figure 1 shows the actual features of the PFHE used in this study. Figure 2 shows schematic drawing of PFHE fins, and the geometric dimensions are listed in Table 1. Figure 3 presents a schematic diagram of its internal geometric structure. The PFHE can be geometrically divided into 'finned area' and 'distribution area'. Since each channel $(\mathrm{A} \sim \mathrm{C})$ has one inlet port and one outlet port respectively, the water and refrigerant flow are distributed into the layers through the distribution area. The effective length and width represent the length and width of the 'finned area'. The length and width except for the effective one mean those of distribution area. The multi-stream structure PFHE consists of staking fins, side bars, parting sheets, and covering plates. The PFHE in this study comprises three types of channels, namely A, B, and C, with two layers assigned to each channel. Thus, the heat exchanger has six layers with the order of $\mathrm{C}-\mathrm{A}-\mathrm{B}-\mathrm{A}-\mathrm{B}-\mathrm{C}$, where the refrigerant flows through channel $\mathrm{A}$ and water flows through channels $\mathrm{B}$ and $\mathrm{C}$. Because layers of channel $C$ are placed at both outer sides, the heat exchanger can be used as a two-stream mode if no fluid flows through channel C.

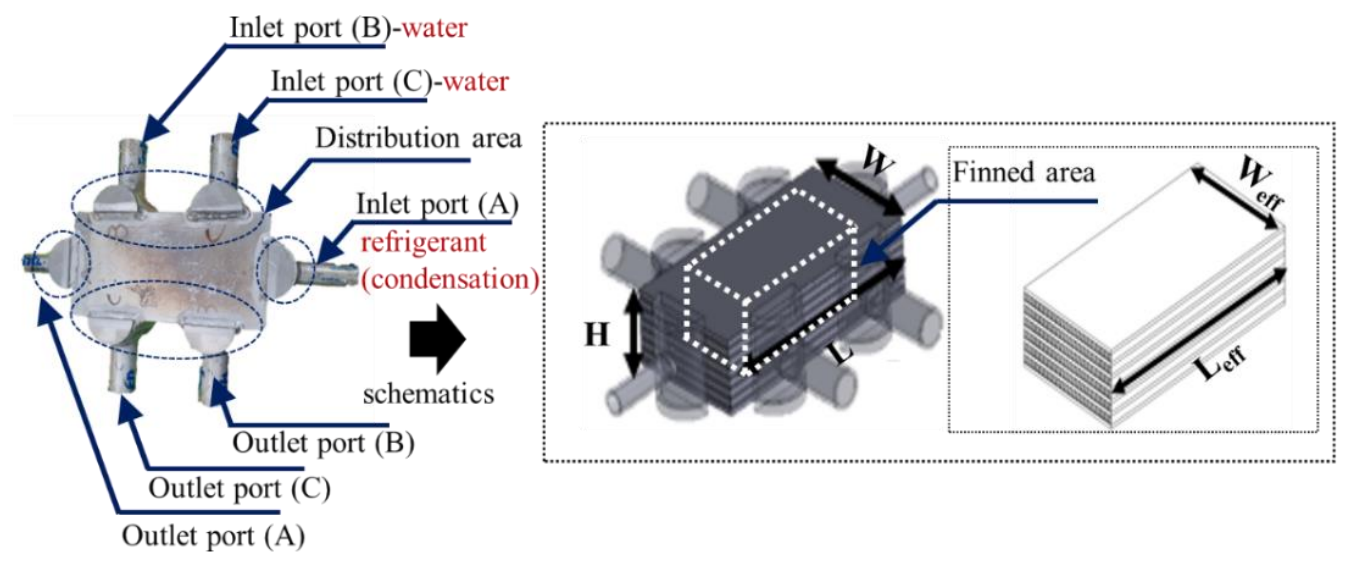

Figure 1. Feature of Plate-Fin Heat Exchanger (PFHE).
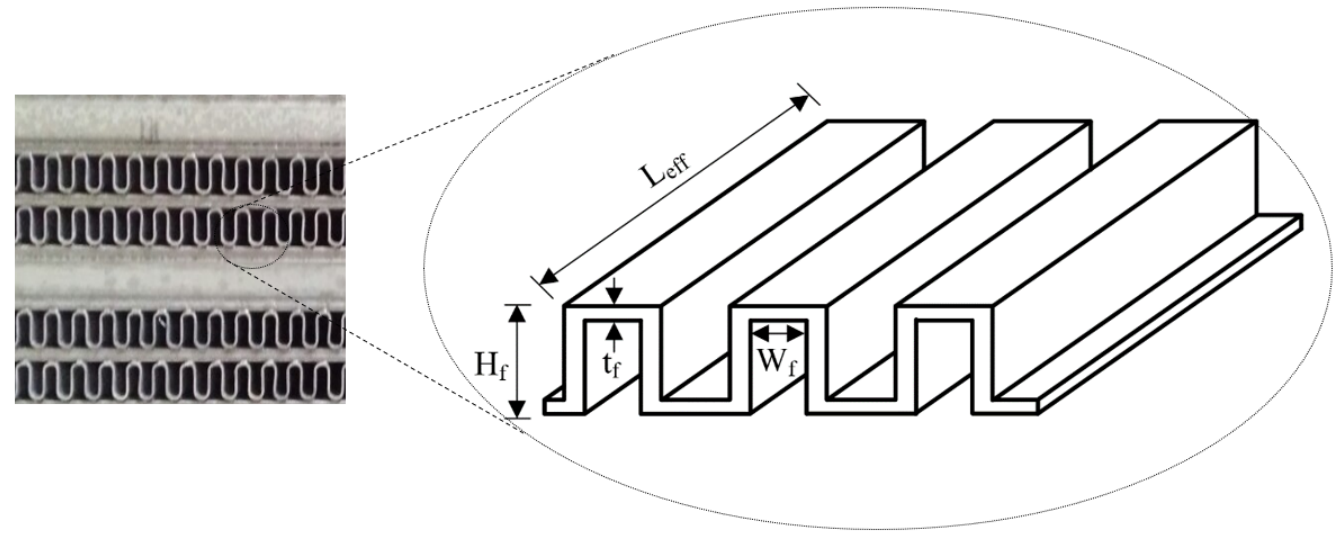

Figure 2. Schematic drawing of the PFHE fin. 
Insulated

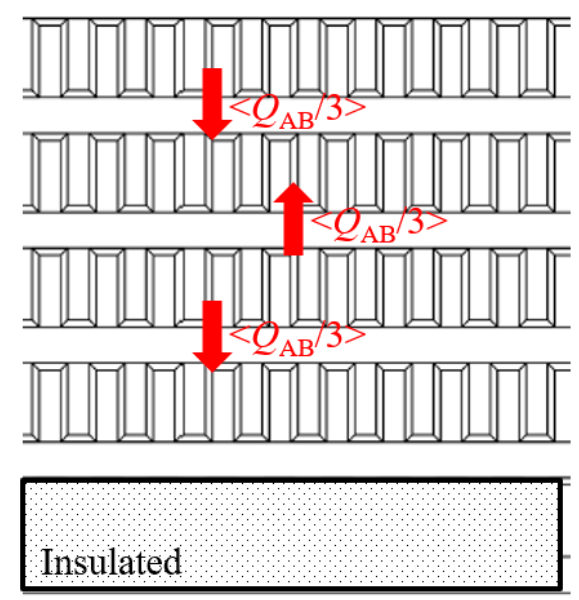

(a)
Channel A: R-134a

$<$ condensation>

Channel B: water

<single-phase>

Channel A: R-134a

$<$ condensation>

Channel B: water $<$ single-phase $>$

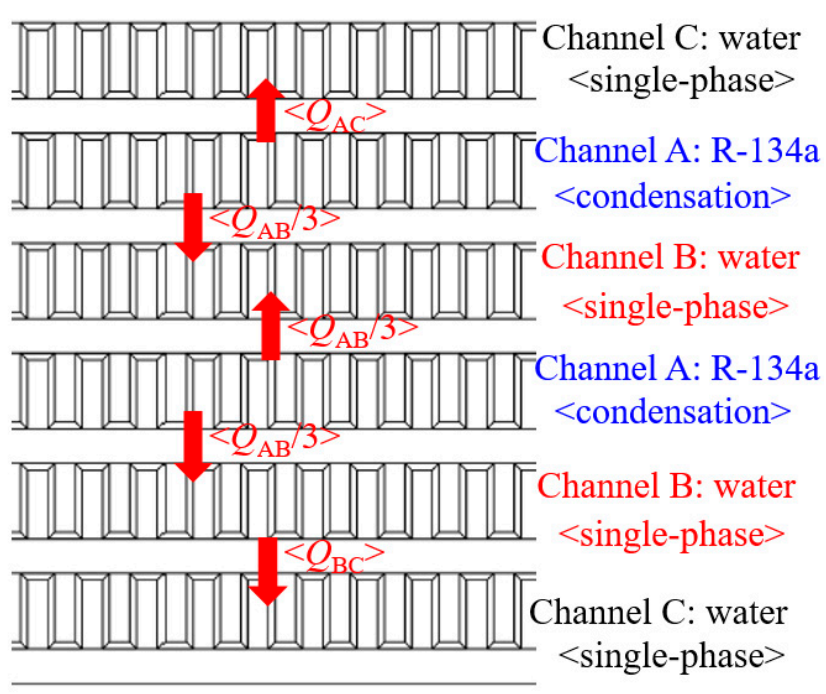

(b)

Figure 3. Schematic diagram of internal geometric structure of PFHE. (a) 2-stream PFHE. (b) Multi-stream PFHE.

Table 1. Summary of geometric dimensions of the PFHE.

\begin{tabular}{ccc}
\hline Parameters & Mark & Value \\
\hline PFHE height $(\mathrm{mm})$ & $H$ & 66.18 \\
\hline PFHE length $(\mathrm{mm})$ & $L$ & 244 \\
\hline PFHE width $(\mathrm{mm})$ & $W$ & 124 \\
\hline Effective length $(\mathrm{mm})$ & $L_{\text {eff }}$ & 80 \\
\hline Effective width $(\mathrm{mm})$ & $W_{\text {eff }}$ & 40 \\
\hline Staking pattern & $\mathrm{n} / \mathrm{a}$ & C-A-B-A-B-C \\
\hline Fin type & $\mathrm{n} / \mathrm{a}$ & Plain fin \\
\hline Fin hydraulic diameter $(\mathrm{mm})$ & $D_{\mathrm{h}}$ & 1.47 \\
\hline Fin height $(\mathrm{mm})$ & $H_{\mathrm{f}}$ & 6.4 \\
\hline Fin thickness $(\mathrm{mm})$ & $t_{\mathrm{f}}$ & 0.5 \\
\hline Fin frequency $($ Fin Per Inch) & $\mathrm{n} / \mathrm{a}$ & 19 \\
\hline Flow path width $(\mathrm{mm})$ & $W_{\mathrm{f}}$ & 0.84 \\
\hline
\end{tabular}

\subsection{Experimental System Description}

Figure 4 shows a schematic diagram of the experimental apparatus for analyzing the condensation heat transfer characteristics of a multi-stream PFHE. As mentioned earlier, the PFHE consists of three channels, namely A, B, and C, with two layers assigned to each channel. The refrigerant flows through channel $\mathrm{A}$ and water flows through channels $\mathrm{B}$ and $\mathrm{C}$; therefore, the experimental system consists of one refrigerant loop and two water loops. In the two-stream PFHE experiments, there is no water flow in channel $\mathrm{C}$ to provide an insulated surface condition.

First, the refrigerant flow rate was controlled by an inverter-integrated magnetic gear pump. An electric heater with a capacity of $7.5 \mathrm{~kW}$ was used to generate two-phase or vapor state refrigerant at the refrigerant inlet, and its capacity was controlled using a connected slide-AC to adjust the vapor quality of the refrigerant flow. The superheated vapor or two-phase refrigerant flow was then condensed by exchanging heat with water flow as it passed through the test section and then turned into a subcooled liquid in the receiver tank, where the heat exchanger coil connected to the separate brine chiller was 
submerged in the refrigerant liquid. Pressure sensors and T-type thermocouples were installed at the heater inlet and on both sides of the test section. The mass flow rate of the refrigerant was measured using a mass flow meter installed after the magnetic gear pump. In addition, the power meter connected to the heater enables the calculation of the vapor quality of the refrigerant flow at the inlet of the test section. The pressure drop across the heat exchanger was measured using a differential pressure sensor. In terms of the water loop, cooling water circulates channels A and B by the water pump to remove condensation heat, and the constant temperature baths keep the water temperature from increasing. The water flow rate can be controlled by the inverter, which is connected to the water circulation pumps, and the control valve installed at the outlet side of the pump. The experiments were conducted with steady state. Revolution per minute (RPM) of the gear pump, capacity of electric heater, and flow rate of the brine are controlled to achieve experimental conditions. After finishing adjustments, the system was kept for about $30 \mathrm{~min}$ until the working conditions become stable to achieve steady state condition. Here, if the desired operation condition is not reached, the experimental variables stated above should be adjusted again. The turbine water flow meter measures the water flow rate, and T-type thermocouples measure the water temperature at each key point. Table 2 provides uncertainty in measure and calculated vales. The following Equation (1) for the combined uncertainties of the measured parameters $\left(\omega_{x_{1}}, \omega_{x_{2}} \cdots \omega_{x_{n}}\right)$ was used to calculate the uncertainty of the evaluated parameters $\left(\omega_{X}\right)$.

$$
\omega_{X}=\sqrt{\left(\frac{\partial X}{\partial x_{1}}\right)^{2} \omega_{x_{1}}^{2}+\left(\frac{\partial X}{\partial x_{2}}\right)^{2} \omega_{x_{2}}^{2}+\cdots+\left(\frac{\partial X}{\partial x_{n}}\right)^{2} \omega_{x_{n}}^{2}}
$$

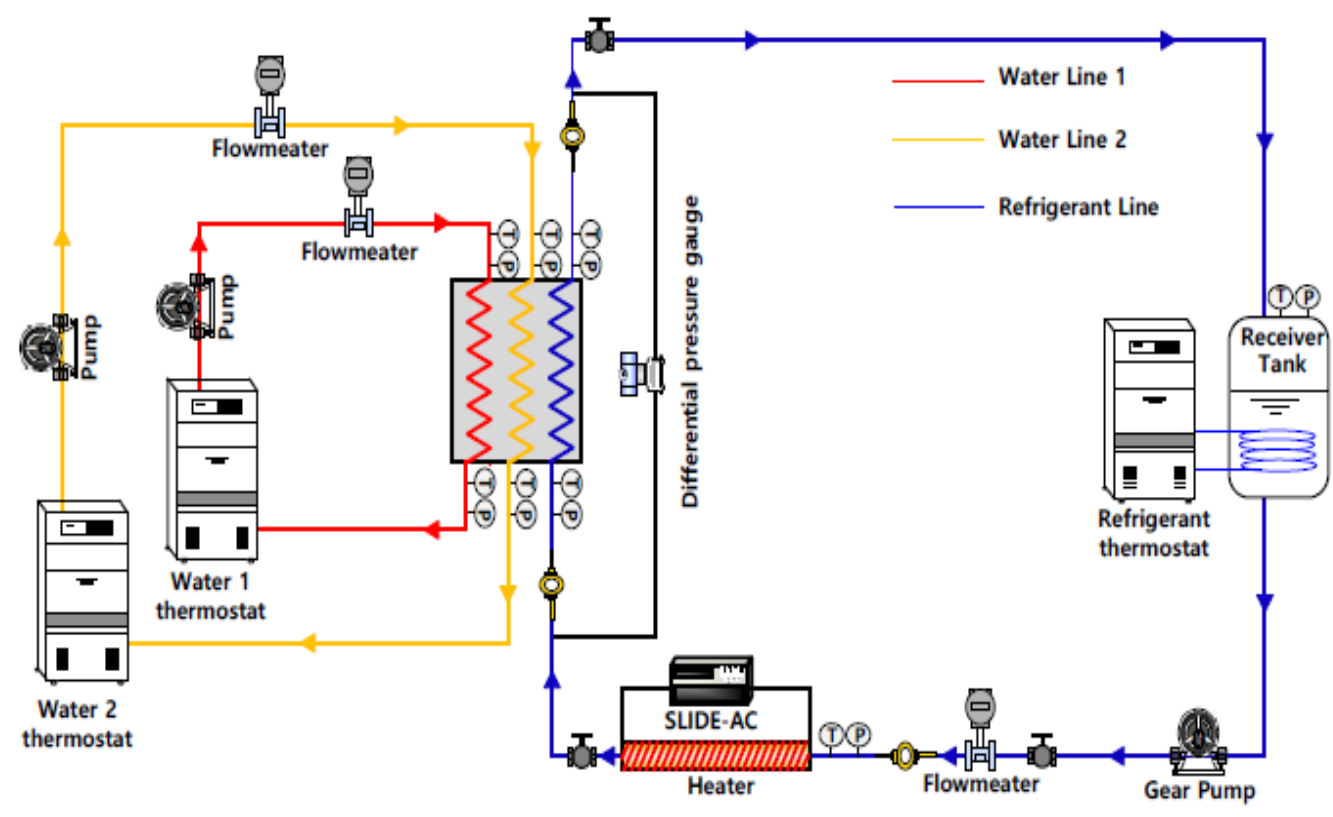

Figure 4. Schematic diagram of multi-stream PFHE experimental apparatus.

Table 2. Uncertainties in measured and calculated values.

\begin{tabular}{cc}
\hline Parameter & Experiment Condition \\
\hline Pressure (Model PSC, Sensys) & $\pm 0.25 \%$ F.S \\
\hline Temperature (PT-100) & $\pm 0.25{ }^{\circ} \mathrm{C}$ \\
\hline Water flow rate (Turbine flowmeter, Corea Flow) & $\pm 1.0 \%$ F.S \\
\hline Heat flux (Electric heater) & $\pm 3.0 \%$ Reading \\
\hline Heat transfer rate (Calculated) & $\pm 6 \%$ \\
\hline Heat transfer coefficient (Calculated) & $\pm 10 \%$ \\
\hline
\end{tabular}




\section{Single-Phase Heat Transfer in Two-Stream PFHE}

\subsection{Analysis Methodology}

In advance of experiments on condensation heat transfer characteristics, single-phase heat transfer in a two-stream PFHE is analyzed to derive the single-phase HTC through the Wilson plot method. There are two ways to estimate the condensation HTC from the experiment: (1) based on the measured heat exchanger wall temperature and (2) based on the experimentally obtained overall HTC $(U)$. To implement the second method, the single-phase convection HTC should be known, as shown in Equation (2). Here, $R_{\mathrm{ov}}$ means overall heat transfer resistance and $R_{\mathrm{c}}$ is heat transfer resistance of colder side.

$$
R_{\mathrm{ov}}=R_{\mathrm{h}}+R_{\mathrm{cond}}+R_{\mathrm{c}}
$$

The model for single-phase convection is expressed in Equation (3) and can be found in the research of Fernandez-Seara et al. [24]. Here, $D_{\mathrm{h}}$ means hydraulic diameter, $\operatorname{Pr}$ is Prandtl number, $R e$ is Reynolds number, $k_{\mathrm{c}}$ is thermal conductivity of colder side, and $C_{1}$ and $n$ are constants that should be fitted by the Wilson plot method.

$$
h_{\mathrm{c}}=\frac{k_{\mathrm{c}}}{D_{\mathrm{h}}} C_{1} \operatorname{Re}_{\mathrm{c}}{ }^{n} \operatorname{Pr}_{\mathrm{c}}{ }^{1 / 3}
$$

The following procedures were used to linearize Equation (2) by applying the Wilson plot method, which is one of the methods for estimating the HTC by utilizing the concept of thermal resistance. Assuming that the HTC of the hotter side $\left(h_{\mathrm{h}}\right)$ is constant, the sum of the heat transfer resistance of the hotter side $\left(R_{\mathrm{h}}\right)$ and conduction $\left(R_{\text {cond }}\right)$ can be substituted with constant $C_{2}$, which can be estimated by the Wilson plot method [24-26].

$$
R_{\mathrm{h}}+R_{\text {cond }}=C_{2}
$$

Equation (2) can be rearranged by considering Equations (3) and (4). Because linearization is required, the terms in Equation (5) are simplified as shown in Equation (6).

$$
\begin{gathered}
R_{\mathrm{ov}}=\frac{1}{U}=\frac{1}{C_{1}} \times \frac{1}{\frac{k_{\mathrm{c}}}{D_{\mathrm{h}}} \operatorname{Re}_{\mathrm{c}}{ }^{n} \operatorname{Pr}_{\mathrm{c}}{ }^{1 / 3}}+C_{2} \\
y_{1}=\frac{1}{C_{1}} \times x_{1}+C_{2}
\end{gathered}
$$

Here,

$$
y_{1}=\frac{1}{U}
$$

And,

$$
x_{1}=\frac{1}{\frac{k_{\mathrm{c}}}{D_{\mathrm{h}}} \operatorname{Re}_{\mathrm{c}}{ }^{n} \operatorname{Pr}_{\mathrm{c}}{ }^{1 / 3}}
$$

It should be noted that the initial value of ' $n$ ' in Equation (3) should be assumed to proceed with the procedures described above. That is, there should be another step to verify whether the assumed ' $n$ ' value is acceptable. For this, the iteration calculation method was applied to the following equations to conduct the regression analysis. Equation (5) can be written differently as following to proceed iteration methodology.

$$
\begin{gathered}
\left(\frac{1}{U}-C_{2}\right) \times\left(\frac{k_{\mathrm{c}}}{D_{\mathrm{h}}} \operatorname{Pr}_{\mathrm{c}^{3}}{ }^{\frac{1}{3}}\right)=\frac{1}{C_{1} \operatorname{Re}_{\mathrm{c}}{ }^{n}} \\
y_{2}=\frac{1}{C_{1} \operatorname{Re}_{\mathrm{c}}{ }^{n}}
\end{gathered}
$$




$$
\begin{gathered}
\ln \left(y_{2}\right)=-\ln \left(C_{1}\right)-n \times \ln \left(R e_{\mathrm{c}}\right) \\
Y_{2}=\ln \left(y_{2}\right) \\
X_{2}=\ln \left(R e_{\mathrm{c}}\right) \\
Y_{2}=-n \times X_{2}-\ln \left(C_{1}\right)
\end{gathered}
$$

Because the value of ' $C_{1}$ ' in Equation (9) is obtained from Equation (6), it is possible to compare the assumed initial ' $n$ ' value with the newly fitted value using Equation (14). If these two values are not similar enough, the entire process is repeated from the beginning by substituting the initial ' $n$ ' value with the newly fitted value. If the difference between these two values is less than 0.01 , it is assumed to be the proper value of ' $n$ '.

\subsection{Heat Transfer Correlation (Single-Phase)}

Figure 5 presents the Wilson plot charts for determining the single-phase HTC. Here, the flow rate of R-134a remained constant, and that of water was varied to derive the Nusselt number from the experimental results. Equation (15) represents the derived equation for obtaining the Nusselt number of the water side.

$$
N u=0.00137 \operatorname{Re}_{\mathrm{w}}^{1.42} \operatorname{Pr}_{\mathrm{w}}^{1 / 3}
$$
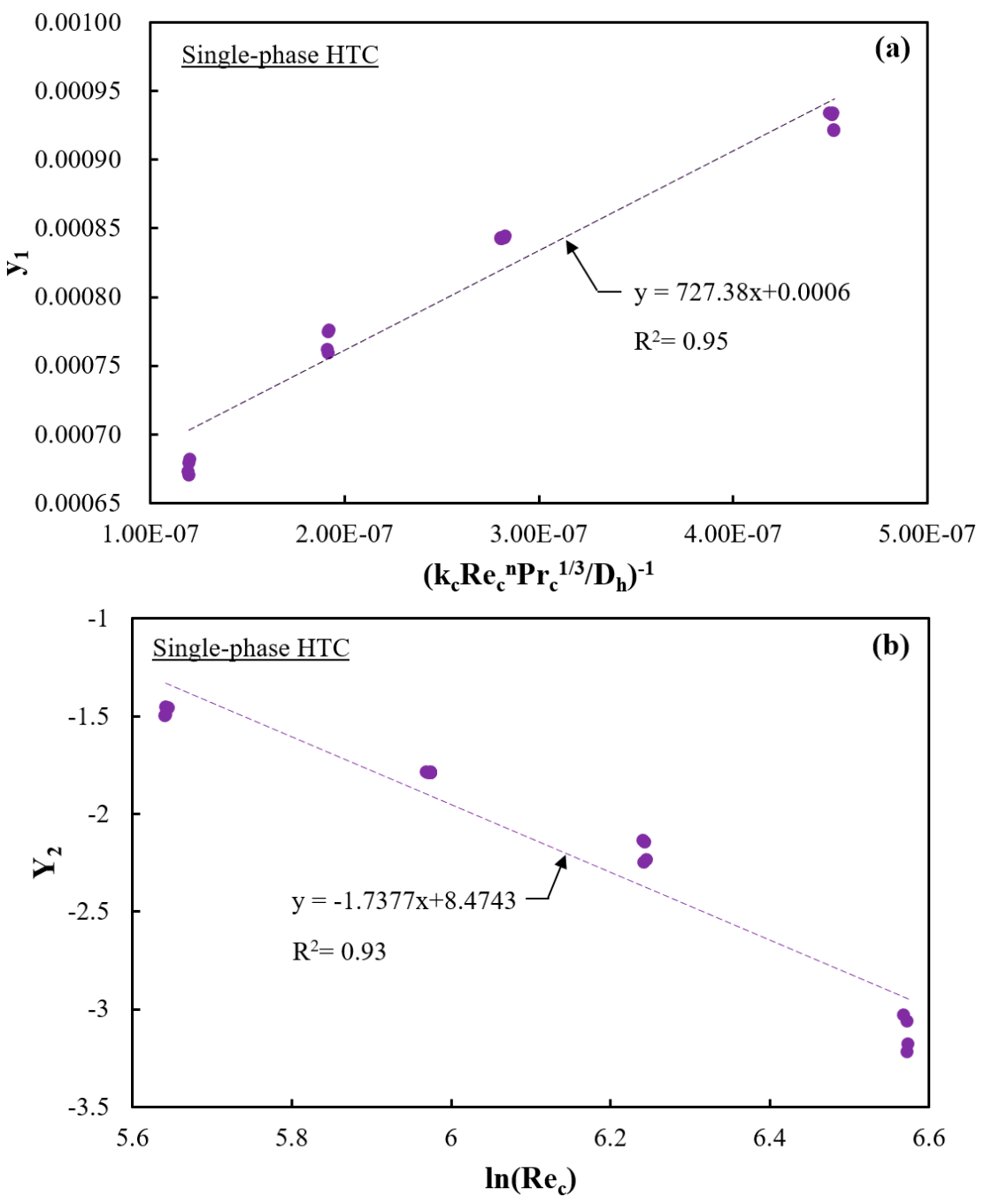

Figure 5. (a,b) Wilson plot charts for deciding water side single-phase convection heat transfer coefficient. 


\section{Condensation Heat Transfer in Two-Stream PFHE}

\subsection{Analysis Methodology}

Experiments for estimating condensation heat transfer were conducted by adjusting the mass flux, heat flux, and saturation pressure of the test section at various inlet and outlet average vapor quality conditions. The experimental conditions for these parameters are listed in Table 3. The mass flux was varied by adjusting the rotating speed of the magnetic gear pump for the circulating refrigerant. Mass flux $(G)$ is calculated based on cross sectional area $\left(A_{\mathrm{c}}\right)$ and the mass flow rate $(m)$, that is $G=m / n A_{\mathrm{c}}$. Here, $n=W_{\text {eff }} /\left(W_{\mathrm{f}}+t_{\mathrm{f}}\right) \times 2$, and $\mathrm{A}_{\mathrm{c}}=\left(H_{\mathrm{f}}-t_{\mathrm{f}}\right) \times W_{\mathrm{f}}$. The detailed geometric information can be found in Table 1 . The heat flux was changed by controlling the temperature of the cooling water, which absorbed the heat of condensation. The saturation pressure of the refrigerant loop was controlled by adjusting the flow rate of the brine that circulated the brine chiller. Various average vapor quality conditions were prepared by controlling the capacity of the electric heater installed at the inlet of the test section.

Table 3. Summary of experimental conditions.

\begin{tabular}{cc}
\hline Parameter & Experiment Condition \\
\hline $\begin{array}{c}\text { Quality } \\
\text { (average of inlet and outlet) }\end{array}$ & $0.2 \sim 0.9$ \\
\hline Mass flux & $70 \sim 130 \mathrm{~kg} / \mathrm{m}^{2} \mathrm{~s}$ \\
\hline Heat flux & $12 \sim 20 \mathrm{~kW} / \mathrm{m}^{2}$ \\
\hline Saturation pressure & $1.08 \sim 1.27 \mathrm{MPa}[\mathrm{abs}]$ \\
\hline
\end{tabular}

\subsection{Condensation Heat Transfer Characteristics}

\subsubsection{Effect of Mass Flux}

The mass flow of the refrigerant was controlled at three different levels $(70,100 \mathrm{~s}$, and $130 \mathrm{~kg} / \mathrm{m}^{2} \mathrm{~s}$ ) to determine the effect on heat transfer and pressure under various average vapor quality conditions. The mass flux of the refrigerant can be changed by adjusting the RPM of the gear pump. Once the RPM is changed, not only the mass flux but also the average vapor quality at the inlet and outlet of the test section are changed. The capacity of the electric heater should also be controlled to provide various average vapor quality conditions. The refrigerant pressure was affected once the electrical heater was adjusted, which caused a change in the heat flux condition. Therefore, the cooling water temperature and mass flow rate of the brine should be adjusted until the target conditions are reached.

Figure 6 depicts the effects of the refrigerant mass flux on the condensation HTC. Two major tendencies can be found in the results: a higher mass flux results in a higher condensation HTC and a higher vapor quality results in a higher condensation HTC. The fundamental reasons for both are related to the Reynolds number and Nusselt number. As the mass flux $(\dot{G})$ increases, the Reynolds number, which greatly affects the Nusselt number, tends to increase. That is, the effect of turbulence tends to increase owing to the increased inertial force at a higher mass flux. A higher vapor quality $(x)$ refers to a higher equivalent mass flux $\left(\dot{G}_{\mathrm{eq}}\right)$, as shown in Equation (16) [27]. It is also notable that the effect of the mass flux becomes more influential at higher vapor quality. The velocity of the vapor and liquid phase becomes higher at the higher vapor quality. That means shear stress at the interface of the vapor and liquid layer becomes higher, which results in the more active turbulence. The more active turbulent can be connected to the higher heat transfer performance. The same approach in analysis of effect of vapor quality and mass flux can be found in Zhang et al. [28], Goss Jr and Passos [29]. 


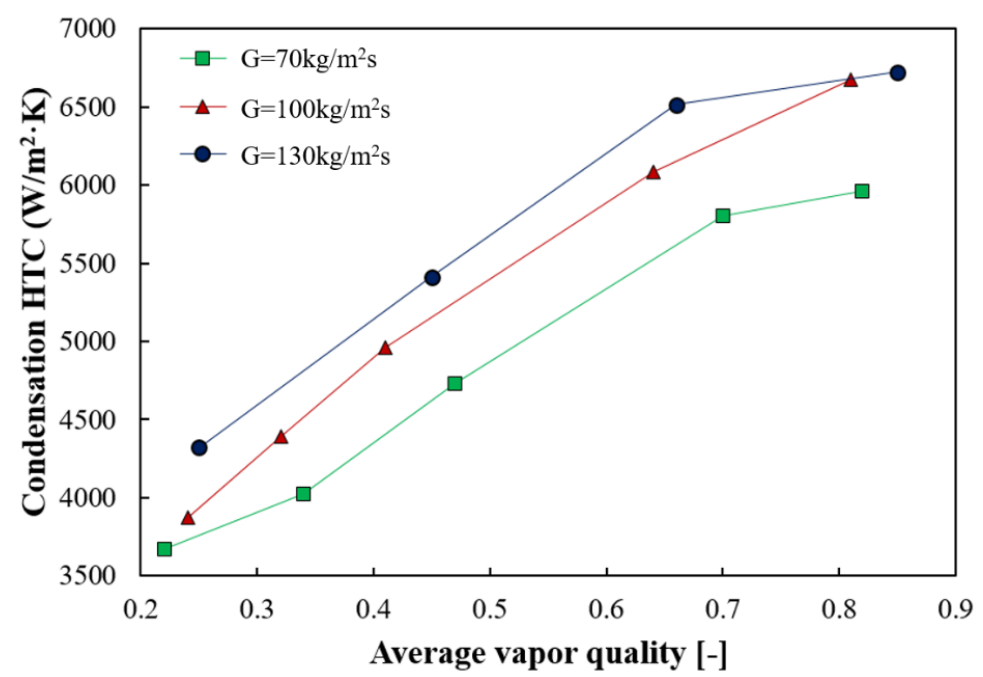

Figure 6. Variation of condensation HTC according to mass flux at various vapor quality condition.

$\rho_{\mathrm{l}}$ and $\rho_{\mathrm{g}}$ are liquid and gas density, respectively. In Equation (17), $R e_{\mathrm{eq}}$ denotes the equivalent Reynolds number and $\mu_{1}$ is the viscosity of liquid.

$$
\begin{gathered}
\dot{G}_{\mathrm{eq}}=\dot{G}\left[(1-x)+x\left(\frac{\rho_{\mathrm{l}}}{\rho_{\mathrm{g}}}\right)^{0.5}\right] \\
\dot{R} e_{\mathrm{eq}}=\frac{\dot{G}_{\mathrm{eq}} D_{\mathrm{h}}}{\mu_{1}}
\end{gathered}
$$

Moreover, the increase in the condensation HTC with increasing refrigerant mass flux from 70 to $100 \mathrm{~kg} / \mathrm{m}^{2} \mathrm{~s}$ was relatively smaller than that of the case from 100 to $130 \mathrm{~kg} / \mathrm{m}^{2} \mathrm{~s}$. Therefore, it can be presumed that the positive effect of increasing mass flux on condensation HTC is limited, and the derived correlation may be effective within a certain range of the mass flux.

Figure 7 depicts the effects of the refrigerant mass flux on the pressure drop. The pressure drop in the test section tended to increase as the vapor quality increased, and the increment increased as the vapor became dominant. Jassim et al. [30] pointed out that the degree of pressure drop of a two-phase fluid tends to increase with an increase in its kinetic energy per unit volume. Increased vapor quality represents enhanced kinetic energy, which results in a more active turbulent flow.

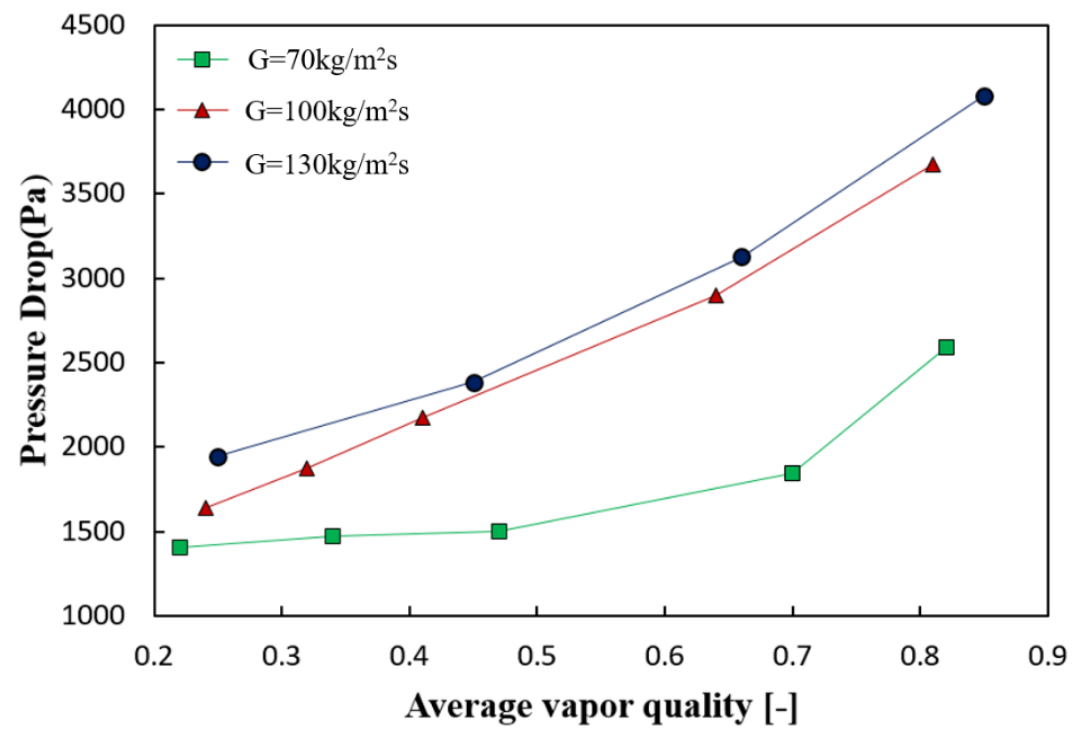

Figure 7. Variation of pressure drop according to mass flux at various vapor quality condition. 


\subsubsection{Effect of Heat Flux}

The heat flux was controlled at three different levels $\left(12,16\right.$, and $\left.20 \mathrm{~kW} / \mathrm{m}^{2}\right)$ to analyze the effect on heat transfer and pressure drop at various average vapor quality conditions. The gear pump circulates the target mass flux, and the electric heater affects the vapor quality at the inlet of the test section. The heat flux can be controlled by adjusting the water temperature in the test section. As mentioned earlier, this causes a change in the refrigerant pressure. Therefore, the mass flow rate of the brine should be altered to reach the target experimental conditions. It should be noted that the change in pressure also affects the mass flux, which implies that the RPM of the gear pump should be adjusted until it reaches the desired experimental conditions.

Figure 8 depicts the change in the condensation HTC according to the adjustment of the heat flux. It can be observed that the condensation HTC tends to increase with increasing heat flux. The effect of heat flux on condensation HTC is rather minor than that of mass flux, as discussed in Section 4.2.1. The average condensation HTC value of the case with minimum heat flux $\left(12 \mathrm{~kW} / \mathrm{m}^{2}\right)$ is merely $4.6 \%$ higher than that of the case with maximum heat flux $\left(20 \mathrm{~kW} / \mathrm{m}^{2}\right)$. The fact that the effect of heat flux on the condensation HTC is not major can also be found in other literatures [31,32]. According to Sakamatapan et al. [6], change in the momentum of the liquid and vapor phase can be one reason for increasing HTC with respect to increased heat flux. Soliman et al. also pointed out that the momentum contribution will result in increase of the heat transfer coefficient; the momentum term is proportional to rate of change in vapor quality to the direction of heat transfer $(d x / d z)$. The higher heat flux result in the higher value of $d x / d z$, meaning an increase in the momentum and the heat transfer coefficient [33].

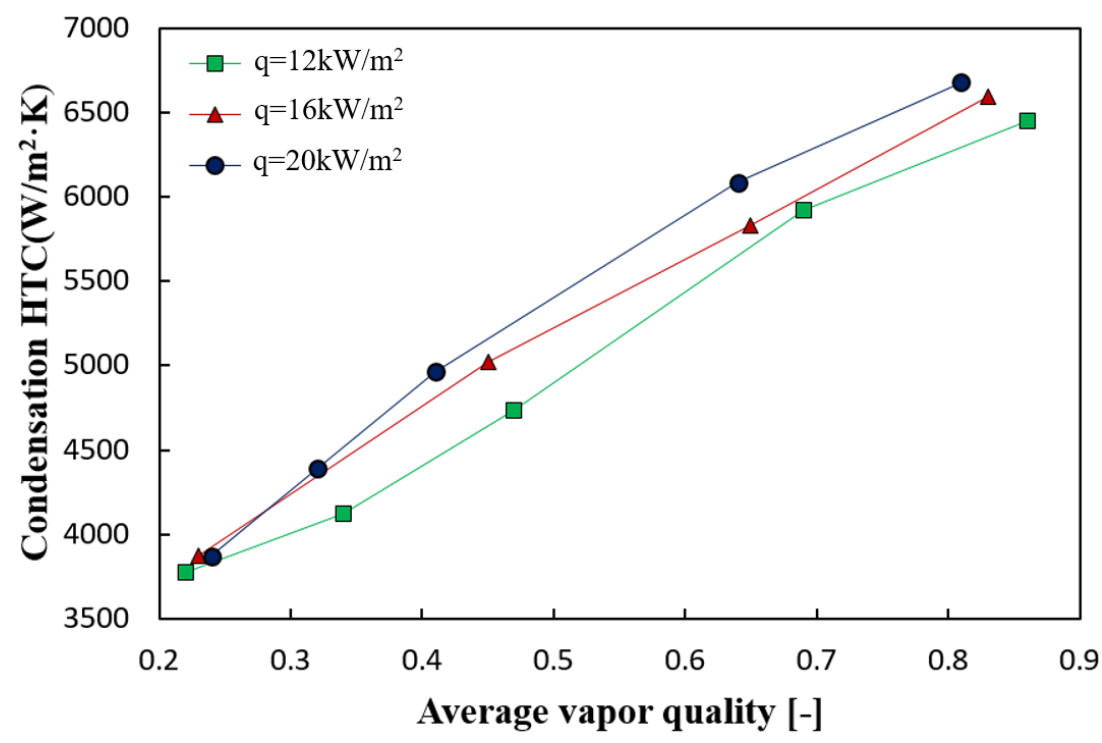

Figure 8. Condensation HTC according to heat flux at various vapor quality condition.

On the other hand, there is no clear finding regarding relation of heat flux with vapor quality because the change in HTC according to heat flux is not major. Difference of HTC of the case 16 and $20 \mathrm{~kW} / \mathrm{m}^{2}$ in lower vapor quality area (0.2-0.5) was smaller than that in higher vapor quality (0.5-0.9). On the other hand, the comparison between the case 12 and $16 \mathrm{~kW} / \mathrm{m}^{2}$ presented the opposite tendency. The research of Sakamatapan et al. [6] also presented a similar tendency.

Figure 9 shows the effect of heat flux on the pressure drop across the test section. This tendency is the same as in the case of adjusting the mass flux. An increase of pressure drop is observed with increasing vapor quality owing to the increased kinetic energy per unit volume. Specifically, a higher vapor portion results in a higher pressure drop. 


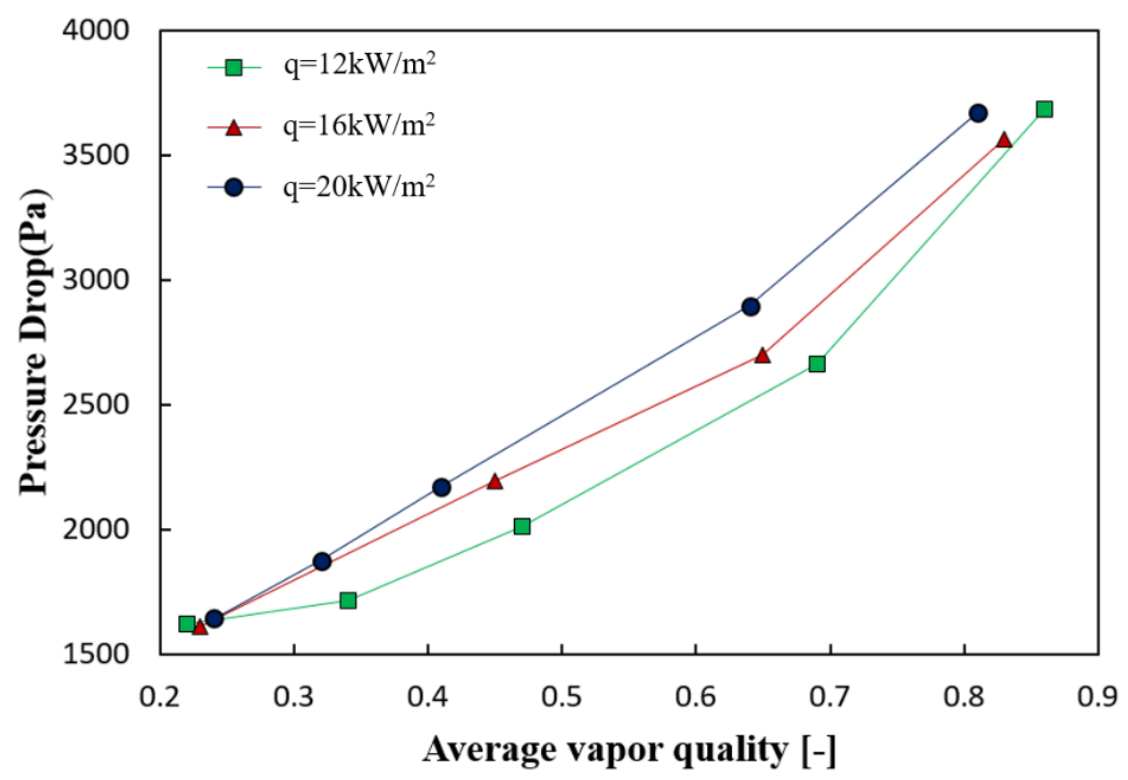

Figure 9. Pressure drop according to heat flux at various vapor quality condition.

\subsubsection{Effect of Saturation Pressure}

The saturation pressure was controlled at three different levels $(1.08,1.17$, and $1.27 \mathrm{MPa})$ to analyze the effect on heat transfer and pressure drop at various average vapor quality conditions.

The experimental methodologies were similar to those of previous cases. First, the capacity of the electric heater was controlled to provide various vapor quality conditions. As mentioned earlier, the refrigerant pressure was affected once the electrical heater was adjusted. Therefore, the cooling water temperature and mass flow rate of the brine should be adjusted until the target conditions are reached.

As presented in Figure 10, the average value of the condensation HTC is 10.7\% higher at a saturation pressure of $1.08 \mathrm{MPa}$ than that at $1.27 \mathrm{MPa}$. Charnay et al. addressed the effect of the thickness of the liquid layer on two-phase heat transfer, which implies that a higher saturation pressure results in a thicker liquid layer [34]. In the same way, the portion of vapor in two-phase flow during the condensation heat transfer tends to decrease, which impedes turbulent flow. According to Rahman et al. [35], the density ratio $\left(\rho_{1} / \rho_{\mathrm{v}}\right)$ becomes smaller as the saturation pressure increases, and the specific volume of vapor decreases as the saturation pressure increases. This means the portion of liquid increases, thereby the liquid layer gets thicker in the certain volume of heat transfer channel. Reduced volume of vapor in the certain volume of heat transfer channel relatively impedes the turbulence, which gives negative effect on the heat transfer. There are other reasons explaining the relation between the HTC and the saturation pressure: shear stress and thermal conductivity of liquid. The viscosity of liquid state R-134a decreases from 0.1648 to $0.1448 \mathrm{mPa} \cdot \mathrm{s}$ as the saturation temperature increases from 40 to $50{ }^{\circ} \mathrm{C}$. The shear stress is proportional to the viscosity, and the higher shear stress is expected to results in the more active turbulence. Lastly, the thermal conductivity of the liquid layer becomes larger as the saturation temperature increases from 40 to $50{ }^{\circ} \mathrm{C}$, which reduces thermal resistance. In addition, the degree of effect of the saturation pressure is relatively similar regardless of the vapor quality. In the low vapor quality area $(0.2-0.5)$, the difference in condensation HTC between 1.08 and $1.27 \mathrm{MPa}$ is about $9 \%$, whereas that of high vapor quality area $(0.5-0.9)$ is about $12.4 \%$.

Figure 11 shows the pressure drop according to the saturation pressure. Owing to the decreased degree of turbulence in two-phase flow, the high saturation pressure results in a pressure drop. 


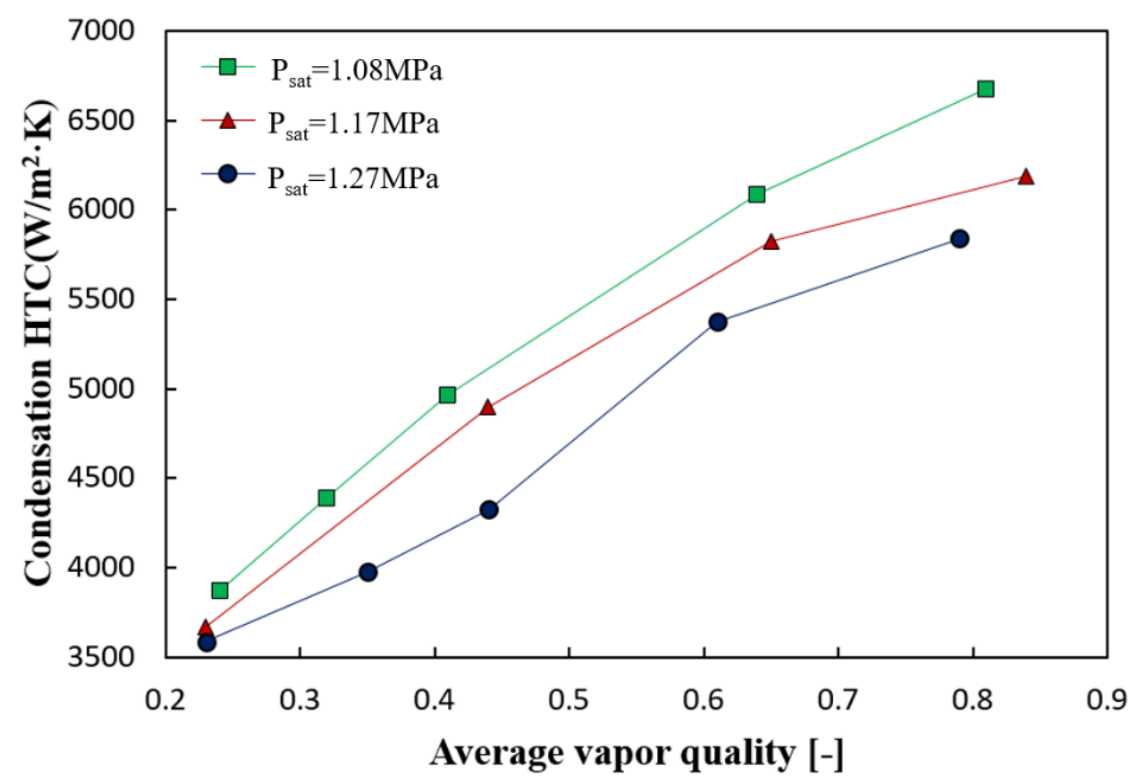

Figure 10. Condensation HTC according to saturation pressure at various vapor quality condition.

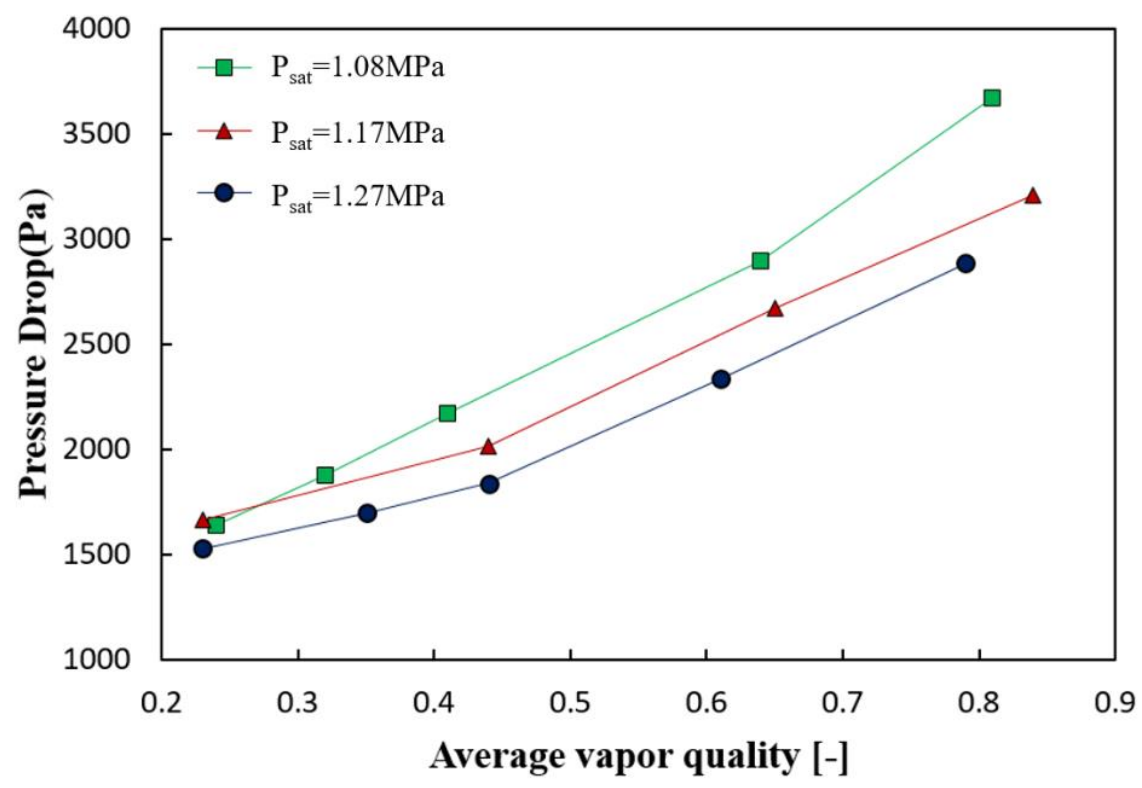

Figure 11. Pressure drop according to saturation pressure at various vapor quality condition.

\subsubsection{Heat Transfer Correlation (2-Stream Condensation)}

The condensation heat transfer correlation for the two-stream PFHE was derived based on the experimental data. As mentioned earlier, the concept of equivalent mass flux and an equivalent Reynolds number [36] is adopted to reflect the effect of both the liquid and vapor in the two-phase flow. Particularly, the two-phase flow is regarded as a homogenous flow. Therefore, it is acceptable that the correlation model in Equation (3), which is used to describe single-phase convection heat transfer, can be used in the case of phase-changing condensation. Based on the experimental data, it can be noted that the mass flux is the most influential parameter among the heat flux and saturation pressure. Similar results have been reported in other studies [7,12]. Because the Reynolds number, that is, the equivalent mass flux of the refrigerant, is dominant in the correlation model, it may be possible to describe the condensation heat transfer characteristics successfully. Equation (18) shows the correlation whose constants are fitted based on experimental data at various conditions of mass flux, heat flux, and saturation pressure. 


$$
N u=0.9726 \operatorname{Re} e_{\mathrm{eq}}^{0.5416} \operatorname{Pr}_{\mathrm{w}}{ }^{1 / 3}
$$

To verify the applicability of the correlation, Figure 12 compares the condensation HTC obtained experimentally and calculated from the fitted correlations. The difference between calculated heat transfer coefficient from the derived correlation and the experimentally obtained value presented the average error of approximately $6.5 \%$. The maximum deviation was about $\pm 20 \%$. Also Figure 12 compares the results of present research with other literatures. Akers et al. [27] applied the same correlation model with the present study, and also assumes the two-phase flow to be the homogeneous flow. Bohdal et al. [37] suggested condensation correlation equation in the range of hydraulic diameter of $0.31 \sim 3.30 \mathrm{~mm}$, and the refrigerant and heat exchanger type were R134a and circular tube, respectively.

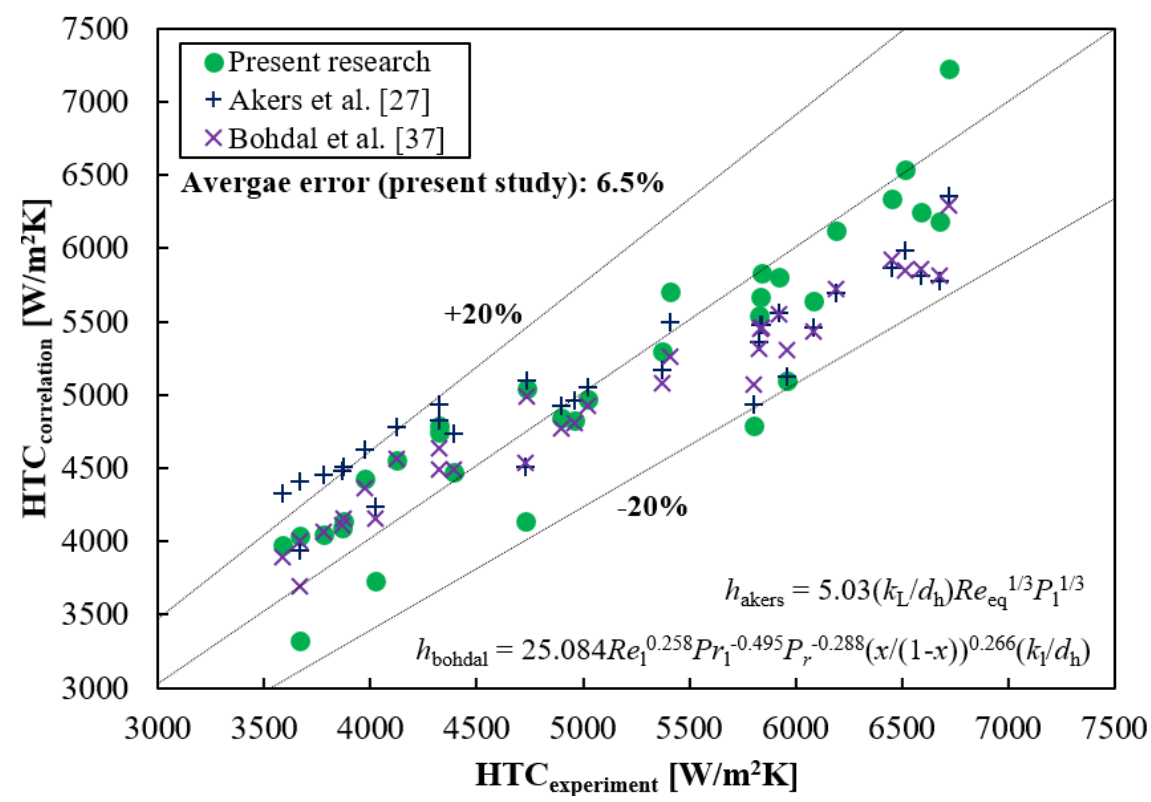

Figure 12. Comparison between experimental and calculated 2-stream condensation HTC.

\section{Condensation Heat Transfer in Multi-Stream PFHE}

\subsection{Analysis Methodology}

Unlike the heat transfer in two-stream PFHE, which is affected by single water flow running through channel $B$, that of multi-stream PFHE is related to two kinds of water flow running through the channels $B$ and $C$, respectively. That is, the effect of both sides should be considered when analyzing multi-stream heat transfer because the fins are in contact with both sides. The half-fin idealization, which assumes that each half of the fin height takes care of the heat transfer from each side, is adopted in this study to reflect the thermal effect. This assumption is considered acceptable and shows only minor errors compared to the calculation based on the modified fin efficiency suggested by Prasad [18], provided that the temperature difference between both sides is not too large.

The following equations describe the analysis methodology of condensation heat transfer in a multi-stream PFHE. $A_{\mathrm{p}}$ and $A_{\mathrm{f}}$ refer to the area of the primary and fin, respectively.

$$
\begin{aligned}
& Q_{\mathrm{AB}}=3 \times U_{\mathrm{AB}} \frac{\left(A_{\mathrm{p}}+\eta A_{\mathrm{f}}\right)}{2} \Delta T_{\mathrm{LMTD}, \mathrm{AB}} \\
& Q_{\mathrm{BC}}=3 \times U_{\mathrm{BC}} \frac{\left(A_{\mathrm{p}}+\eta A_{\mathrm{f}}\right)}{2} \Delta T_{\mathrm{LMTD}, \mathrm{BC}} \\
& Q_{\mathrm{AC}}=3 \times U_{\mathrm{CA}} \frac{\left(A_{\mathrm{p}}+\eta A_{\mathrm{f}}\right)}{2} \Delta T_{\mathrm{LMTD}, \mathrm{CA}}
\end{aligned}
$$


Here, the overall HTCs on each side can be calculated using the sum of each thermal resistance, as shown in Equations (22)-(24).

$$
\begin{aligned}
& U_{\mathrm{AB}}=1 /\left(\frac{1}{h_{\mathrm{A}}}+\frac{t_{\text {cond }}}{k_{\text {cond }}}+\frac{1}{h_{\mathrm{B}}}\right) \\
& U_{\mathrm{BC}}=1 /\left(\frac{1}{h_{\mathrm{B}}}+\frac{t_{\text {cond }}}{k_{\text {cond }}}+\frac{1}{h_{\mathrm{C}}}\right) \\
& U_{\mathrm{AC}}=1 /\left(\frac{1}{h_{\mathrm{A}}}+\frac{t_{\text {cond }}}{k_{\text {cond }}}+\frac{1}{h_{\mathrm{C}}}\right)
\end{aligned}
$$

As mentioned earlier, streams $B$ and $C$ are water channels; thus, the heat transfer rates at these channels are obtained according to Equations (25) and (26), respectively. Here, subscripts of $i$ and o mean inlet and outlet, respectively.

$$
\begin{aligned}
& Q_{\mathrm{B}}=\dot{m_{\mathrm{B}}} C_{\mathrm{p}, \mathrm{B}}\left(T_{\mathrm{Bo}}-T_{\mathrm{Bi}}\right)=Q_{\mathrm{AB}}-Q_{\mathrm{BC}} \\
& Q_{\mathrm{C}}=\dot{m_{\mathrm{C}}} C_{\mathrm{p}, \mathrm{C}}\left(T_{\mathrm{Co}}-T_{\mathrm{Ci}}\right)=Q_{\mathrm{BC}}+Q_{\mathrm{AC}}
\end{aligned}
$$

Further, Equation (26) is validated by energy conservation.

$$
Q_{\mathrm{A}}=Q_{\mathrm{B}}+Q_{\mathrm{C}}=Q_{\mathrm{AB}}+Q_{\mathrm{AC}}
$$

By putting Equations (25) and (26) into Equation (27), Equation (28) can be obtained. It should be noted that all parameters in Equation (28) can be acquired experimentally, except for $h_{\mathrm{a}}$, which indicates the condensation HTC in the multi-stream PFHE.

$$
\dot{m_{\mathrm{B}}} C_{\mathrm{p}, \mathrm{B}}\left(T_{\mathrm{B}, \mathrm{o}}-T_{\mathrm{B}, \mathrm{i}}\right)+\dot{m_{\mathrm{C}}} C_{\mathrm{p}, \mathrm{C}}\left(T_{\mathrm{C}, \mathrm{o}}-T_{\mathrm{C}, \mathrm{i}}\right)=Q_{1}+Q_{2}
$$

Here,

$$
\begin{gathered}
Q_{1}=3 \times\left(\frac{1}{h_{\mathrm{A}}}+\frac{t_{\text {cond }}}{k_{\text {cond }}}+\frac{1}{h_{\mathrm{B}}}\right) \frac{\left(A_{\mathrm{p}}+\eta A_{\mathrm{f}}\right)}{2} \Delta T_{\mathrm{LMTD}, \mathrm{AB}} \\
Q_{2}=\left(\frac{1}{h_{\mathrm{B}}}+\frac{t_{\text {cond }}}{k_{\text {cond }}}+\frac{1}{h_{\mathrm{C}}}\right) \frac{\left(A_{\mathrm{p}}+\eta A_{\mathrm{f}}\right)}{2} \Delta T_{\mathrm{LMTD}, \mathrm{CA}}
\end{gathered}
$$

\subsection{Comparison with Two-Stream Case}

As shown in Figure 3, the difference between the multi-stream PFHE and the twostream PFHE is that the multi-stream PFHE has an additional heat transfer surface at the top and bottom. These surfaces were insulated during the two-stream experiments. Top layer $\mathrm{C}$ in which the cooling water flows is adjacent to refrigerant stream A. Conversely, bottom layer $\mathrm{C}$ is in contact with water channel $\mathrm{B}$. From the perspective of the refrigerant, the multi-stream PFHE has one more heat transfer surface compared to the two-stream PFHE. This can be a major reason for the differences in the heat transfer and pressure drop characteristics between the two-stream and multi-stream PFHEs. The detailed description is as follows.

Figure 13 shows a comparison of the pressure drop in the refrigerant flow (channel A) between the two-stream and multi-stream PFHEs. The average pressure drop in the multi-stream is $15 \%$ more than that of the two-stream. In particular, the difference in the high vapor quality area (approximately 0.7 ) is approximately $25 \%$. The formation of liquid droplets disturbs the two-phase flow, which increases the pressure drop. Specifically, the more active the formation of liquid droplets the higher the pressure drop. The multi-stream PFHE has one more heat transfer surface at the top side, which can be connected to the more active formation of droplets. Additionally, it should be noted that the thickness of the liquid layer of the top channel $(\mathrm{C}-\mathrm{A})$ is expected to be thinner than that of the bottom layer (A-B) owing to the effect of gravity. Therefore, it is effective to increase the heat transfer between the surface and two-phase flow. Figure 14 presents a comparison of the 
condensation HTC in the refrigerant flow (channel A) between the two-stream and multistream PFHEs. Owing to the effect of the additional heat transfer surface, the condensation HTC in multi-steam can be increased.

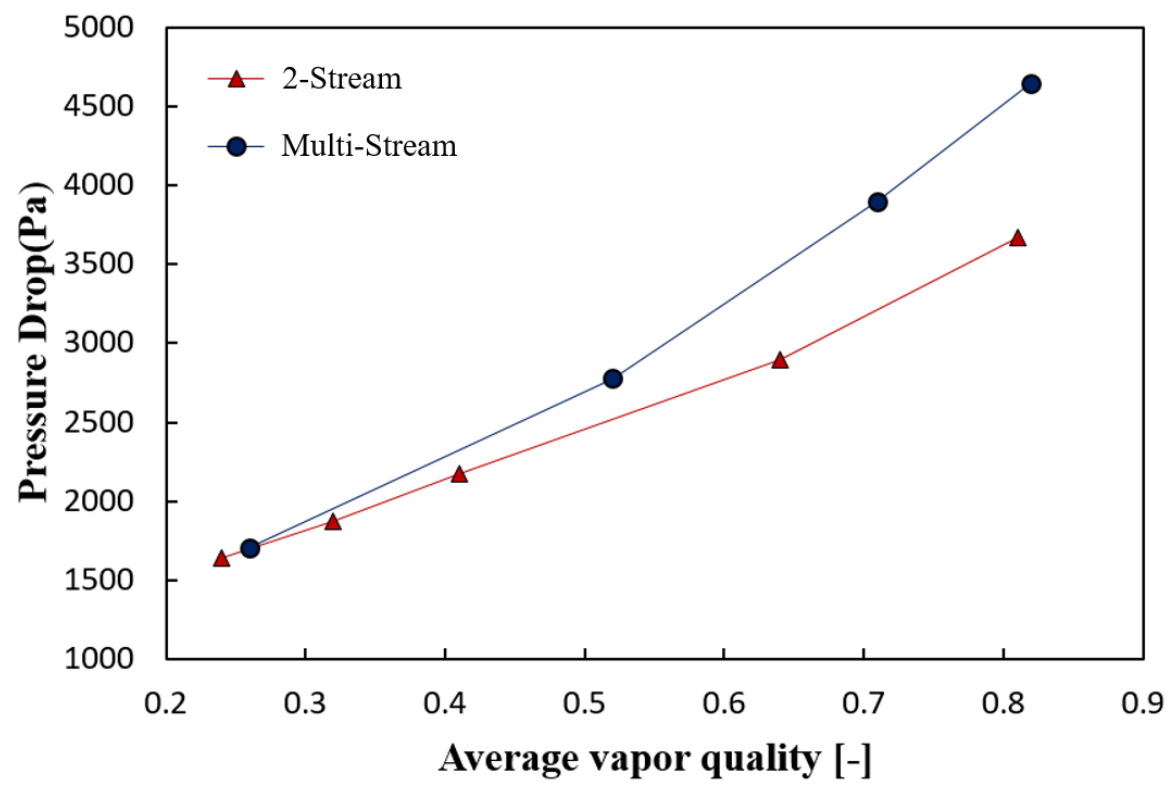

Figure 13. Difference of pressure drop between multi-stream and 2-stream heat transfer.

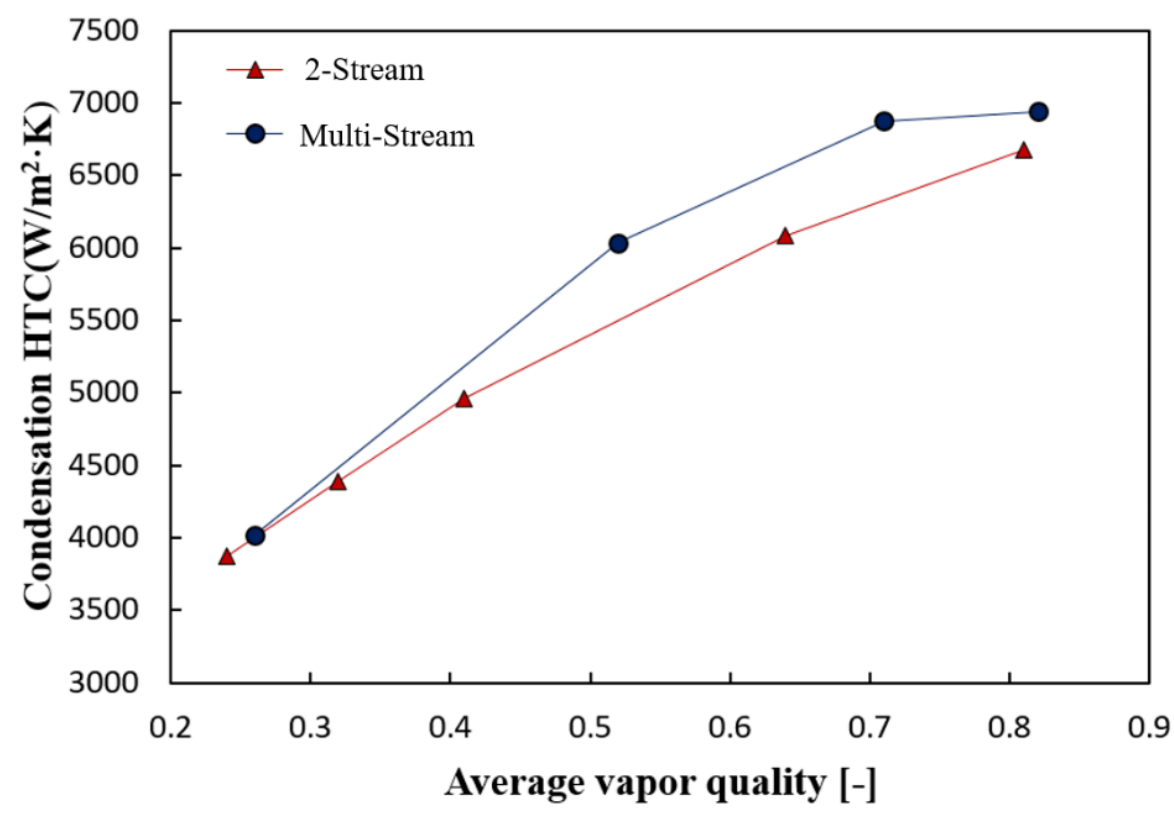

Figure 14. Difference of condensation HTC between multi-stream and 2-stream heat transfer.

Here, for a fair comparison between the two-stream and multi-stream PFHEs, the heat and mass flux conditions were kept the same in both cases. In terms of heat flux, the multi-stream PFHE has two types of heat flux: one from channels $A$ to $B$ and the other from channels $A$ to $C$. When the surface area of one heat transfer surface is denoted by $\theta$, the area of heat transfer from channels A to B becomes $3 \theta$, and that from channels $A$ to $C$ becomes $\theta$. For a fair comparison, the average heat flux through these four layers of the heat transfer surface should be the same as the heat flux of the two-stream PFHE. Therefore, the heat flux from $A$ to $B$ and that from $A$ to $C$ are adjusted to 16.9 and $27.6 \mathrm{~kW} / \mathrm{m}^{2}$, respectively, to yield the average value of $20 \mathrm{~kW} / \mathrm{m}^{2}$. 


\section{Conclusions}

The purpose of this study is to experimentally estimate the heat transfer characteristics of a PFHE. The PFHE, which has a distinct geometric shape, has the advantages of an outstanding heat transfer rate with less volume and weight. In addition, it can have a multi-stream structure, which results in more efficient utilization of the energy compared to a two-stream heat exchanger. To estimate the most influential factor, several parameters, such as the heat flux, mass flux, and saturation pressure are adjusted. The following are the major findings regarding condensation heat transfer and pressure drop in the PFHE.

1. A higher mass flux results in a higher condensation HTC, and a higher vapor quality results in a higher condensation HTC. The main reason for this comes from shear stress. Both conditions commonly cause the higher velocity which results in the higher shear stress at the interface of vapor and liquid.

2. The condensation HTC tends to increase with increasing heat flux owing to the enhanced turbulence of the flow. The effect of heat flux on the condensation HTC was rather minor compared to that of the mass flux.

3. The condensation HTC tends to decrease as the saturation pressure increases because of three major reasons: the thickness of liquid layer, shear stress, and thermal conductivity of liquid. The specific volume of gas and viscosity of liquid are changed according to the saturation pressure. Therefore, thickness of liquid layer and shear stress, which affect turbulence, are expected to be affected.

4. The mass flux is the most influential parameter among the heat flux and saturation pressure. Thus, the equivalent mass flux of the refrigerant (or equivalent Reynolds number) is dominant in the derived correlation model.

5. The pressure drop in the test section tended to increase as the vapor quality increased, and the increment increased as the vapor became dominant.

6. The multi-stream PFHE comprises an additional heat transfer surface. Having one more heat transfer surface for the multi-stream PFHE at the top side can be associated with the active formation of droplets. Therefore, the condensation HTC in the multisteam PFHE can be increased. For the same reason, the average pressure drop in the multi-stream is $15 \%$ more than that of the two-stream PFHE.

Author Contributions: Conceptualization, writing, S.-H.S.; methodology, S.-G.L.; formal analysis, J.-H.Y.; supervision, J.-I.Y.; writing-review and editing, C.-H.S.; visualization, I.-S.E.; investigation, Y.-M.P. All authors have read and agreed to the published version of the manuscript.

Funding: This research is funded by the Korea Agency for Infrastructure Technology Advancement (KAIA) grant funded by the Ministry of Land, Infrastructure and Transport (Grant 21IHTP-B151609-03).

Institutional Review Board Statement: Not applicable.

Informed Consent Statement: Not applicable.

Acknowledgments: This work is supported by the Korea Agency for Infrastructure Technology Advancement (KAIA) grant funded by the Ministry of Land, Infrastructure and Transport (Grant 21IHTP-B151609-03).

Conflicts of Interest: The authors declare no conflict of interest.

\section{Glossary}

\section{Nomenclature}
A Area $\left[\mathrm{m}^{2}\right]$
$C_{1} \quad$ Wilson plot coefficient in Equation (4) [-]
$C_{2} \quad$ Wilson plot coefficient in Equation (5) [-]
$C_{\mathrm{p}} \quad$ Specific heat capacity $[\mathrm{J} / \mathrm{kg} \cdot \mathrm{K}]$
$D_{\mathrm{h}} \quad$ Hydraulic diameter $[\mathrm{m}]$
$\dot{G} \quad$ Mass flux $\left[\mathrm{kg} / \mathrm{m}^{2} \cdot \mathrm{s}\right]$ 


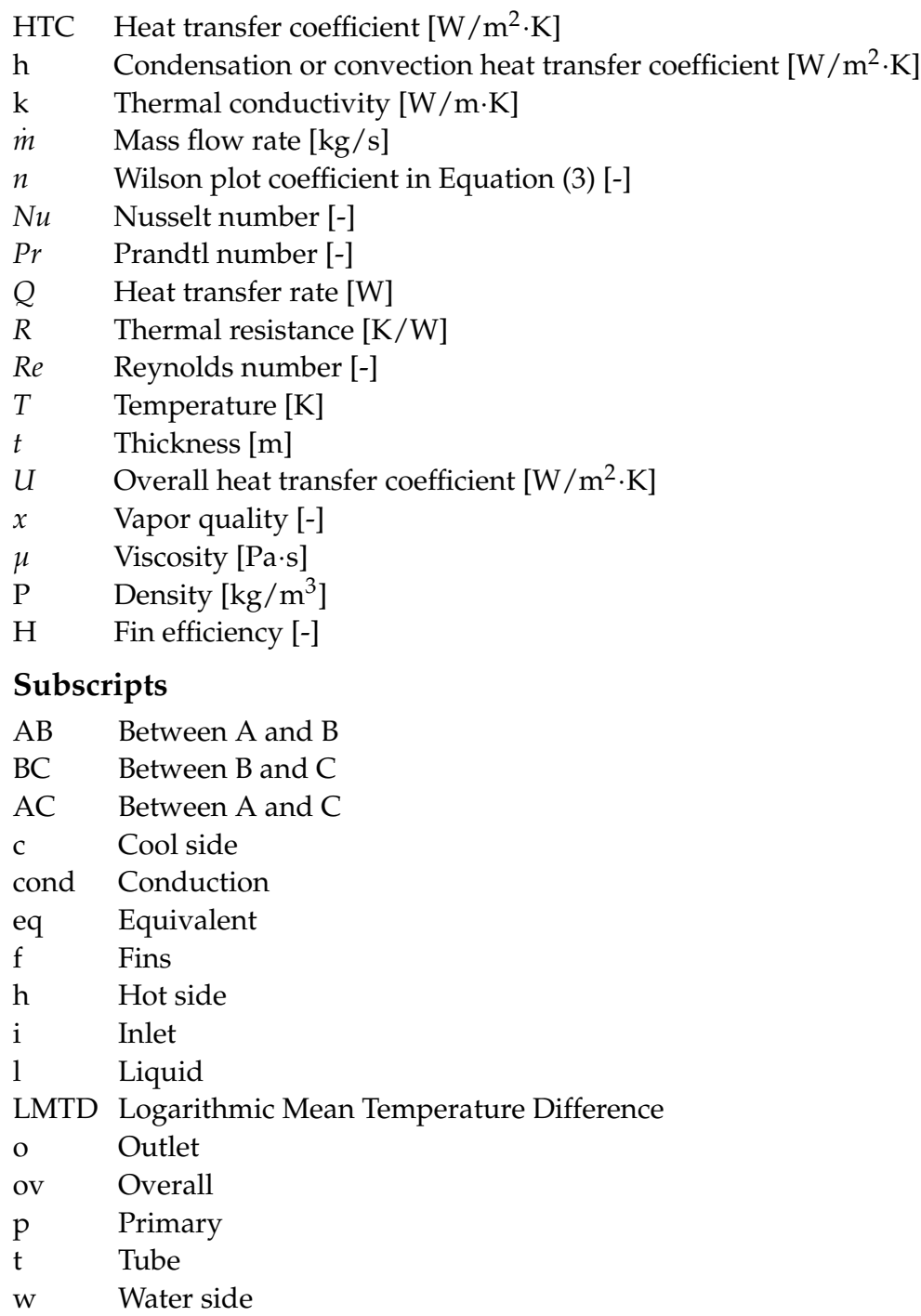

\section{References}

1. Carey, V.P. Two-phase flow in small-scale ribbed and finned passages for compact evaporators and condensers. Nucl. Eng. Des. 1993, 141, 249-268. [CrossRef]

2. Kew, P.A.; Cornwell, K. Correlations for the prediction of boiling heat transfer in small-diameter channels. Appl. Therm. Eng. 1997, 17, 705-715. [CrossRef]

3. Jige, D.; Sugihara, K.; Inoue, N. Evaporation heat transfer and flow characteristics of vertical upward flow in a plate-fin heat exchanger. Int. J. Refrig. 2021, in press. [CrossRef]

4. Yoo, J.W.; Nam, C.W.; Yoon, S.H. Experimental study of propane condensation heat transfer and pressure drop in semicircular channel printed circuit heat exchanger. Int. J. Heat Mass Transf. 2022, 182, 121939. [CrossRef]

5. Amaranatha Raju, M.; Ashok Babu, T.P.; Ranganayakulu, C. Investigation of flow boiling heat transfer and pressure drop of R134a in a rectangular channel with wavy fin. Int. J. Therm. Sci. 2020, 147, 106055. [CrossRef]

6. Sakamatapan, K.; Kaew-On, J.; Dalkilic, A.S.; Mahian, O.; Wongwises, S. Condensation heat transfer characteristics of R-134a flowing inside the multiport minichannels. Int. J. Heat Mass Transf. 2013, 64, 976-985. [CrossRef]

7. Yan, Y.-Y.; Lio, H.-C.; Lin, T.-F. Condensation heat transfer and pressure drop of refrigerant R-134a in a plate heat exchanger. Int. J. Heat Mass Transf. 1999, 42, 993-1006. [CrossRef]

8. Aliabadi, M.K.; Hormozi, F. Performance analysis of plate-fin heat exchangers: Different fin configurations and coolants J. Thermophys. Heat Transf. 2013, 27, 515-525. [CrossRef]

9. Koestoer, R.A.; Novianto, S.; Pamitran, A.S. Heat transfer of single phase flow with natural refrigerant (R-290) in microchannel. AIP Conf. Proc. 2019, 2062, 020058. [CrossRef]

10. Taler, D.; Taler, J. Simple heat transfer correlations for turbulent tube flow. E3S Web Conf. 2017, 13, 1-7. [CrossRef]

11. Khan, M.S.; Zou, R.; Yu, A. Computational simulation of air-side heat transfer and pressure drop performance in staggered mannered twisted oval tube bundle operating in crossflow. Int. J. Therm. Sci. 2021, 161, 106748. [CrossRef] 
12. Lim, J.; Song, K.S.; Kim, D.; Lee, D.C.; Kim, Y. Condensation heat transfer characteristics of R245fa in a shell and plate heat exchanger for high-temperature heat pumps. Int. J. Heat Mass Transf. 2018, 127, 730-739. [CrossRef]

13. Hao, J.H.; Chen, Q.; Ren, J.X.; Zhang, M.Q.; Ai, J. An experimental study on the offset-strip fin geometry optimization of a plate-fin heat exchanger based on the heat current model. Appl. Therm. Eng. 2019, 154, 111-119. [CrossRef]

14. Hornyik, K. Heat Exchangers-Thermal-Hydraulic Fundamentals and Design. Nucl. Technol. 1982, 58, 556. [CrossRef]

15. Guo, K.; Zhang, N.; Smith, R. Design optimisation of multi-stream plate fin heat exchangers with multiple fin types. Appl. Therm. Eng. 2018, 131, 30-40. [CrossRef]

16. Zohuri, B. Compact Heat Exchangers Design for the Process Industry. In Compact Heat Exchangers; Springer International Publishing: Cham, Switzerland, 2017; pp. 57-185. ISBN 9789896540821.

17. Taylor, M.A. Plate-Fin Heat Exchangers: Guide to Their Specification and Use; Heat Transfer and Fluid Flow Services: Amersham, UK, 1987.

18. Prasad, B.S.V. Fin efficiency and mechanisms of heat exchange through fins in multi-stream plate-fin heat exchangers: Formulation. Int. J. Heat Mass Transf. 1996, 39, 419-428. [CrossRef]

19. Prasad, B.S.V. Fin efficiency and mechanisms of heat exchange through fins in multi-stream plate-fin heat exchangers: Development and application of a rating algorithm. Int. J. Heat Mass Transf. 1997, 40, 4279-4288. [CrossRef]

20. Sunden, B. Design Methodology for Multistream Plate-Fin Heat Exchangers in Heat Exchanger Networks. Heat Transf. Eng. 2001, 22, 3-11. [CrossRef]

21. Kays, W.M.; London, A.L. Compact Heat Exchangers; McGraw-Hill: New York, NY, USA, 1984.

22. Picon-Nuñez, M.; Polley, G.T.; Torres-Reyes, E.; Gallegos-Muñoz, A. Surface selection and design of plate-fin heat exchangers. Appl. Therm. Eng. 1999, 19, 917-931. [CrossRef]

23. Ramezanpour Jirandeh, R.; Ghazi, M.; Sotoodeh, A.F.; Nikian, M. Plate-fin heat exchanger network modeling, design and optimization-A novel and comprehensive algorithm. J. Eng. Des. Technol. 2021, 19, 1017-1043. [CrossRef]

24. Fernández-Seara, J.; Uhía, F.J.; Sieres, J.; Campo, A. A general review of the Wilson plot method and its modifications to determine convection coefficients in heat exchange devices. Appl. Therm. Eng. 2007, 27, 2745-2757. [CrossRef]

25. Fernández-Seara, J.; Uhía, F.J.; Sieres, J.; Campo, A. Experimental apparatus for measuring heat transfer coefficients by the Wilson plot method. Eur. J. Phys. 2005, 26. [CrossRef]

26. Fernández-Seara, J.; Uhía, F.J.; Sieres, J. Laboratory practices with the wilson plot method. Exp. Heat Transf. 2007, 20, 123-135. [CrossRef]

27. Akers, W.W.; Deans, H.A.; Crosser, O.K. Condensing heat transfer within horizontal tubes. Chem. Eng. Progr. 1958, 54, $171-176$.

28. Zhang, J.; Kærn, M.R.; Ommen, T.; Elmegaard, B.; Haglind, F. Condensation heat transfer and pressure drop characteristics of R134a, R1234ze(E), R245fa and R1233zd(E) in a plate heat exchanger. Int. J. Heat Mass Transf. 2019, 128, 136-149. [CrossRef]

29. Goss, G.; Passos, J.C. Heat transfer during the condensation of R134a inside eight parallel microchannels. Int. J. Heat Mass Transf. 2013, 59, 9-19. [CrossRef]

30. Jassim, E.W.; Newell, T.A.; Chato, J.C. Refrigerant pressure drop in chevron and bumpy style flat plate heat exchangers. Exp. Therm. Fluid Sci. 2006, 30, 213-222. [CrossRef]

31. Shin, J.S.; Kim, M.H. An Experimental Study of Flow Condensation Heat Transfer Inside Circular and Rectangular Mini-Channels. Heat Transf. Eng. 2005, 26, 36-44. [CrossRef]

32. Yang, C.Y.; Webb, R.L. Condensation of R-12 in small hydraulic diameter extruded aluminum tubes with and without micro-fins. Int. J. Heat Mass Transf. 1996, 39, 791-800. [CrossRef]

33. Soliman, M.; Schuster, J.R.; Berenson, P.J. A General Heat Transfer Correlation for Annular Flow Condensation. J. Heat Transfer 1968, 90, 267-274. [CrossRef]

34. Charnay, R.; Bonjour, J.; Revellin, R. Experimental investigation of R-245fa flow boiling in minichannels at high saturation temperatures: Flow patterns and flow pattern maps. Int. J. Heat Fluid Flow 2014, 46, 1-16. [CrossRef]

35. Rahman, M.M.; Kariya, K.; Miyara, A. An experimental study and development of new correlation for condensation heat transfer coefficient of refrigerant inside a multiport minichannel with and without fins. Int. J. Heat Mass Transf. 2018, 116, 50-60. [CrossRef]

36. Tao, X.; Infante Ferreira, C.A. Heat transfer and frictional pressure drop during condensation in plate heat exchangers: Assessment of correlations and a new method. Int. J. Heat Mass Transf. 2019, 135, 996-1012. [CrossRef]

37. Bohdal, T.; Charun, H.; Sikora, M. Heat transfer during condensation of refrigerants in tubular minichannels. Arch. Thermodyn. 2012, 33, 3-22. [CrossRef] 